\title{
ÉTICA, DIGNIDADE HUMANA E REFORMA TRABALHISTA: ENTREVISTA COM MARLENE SUGUIMATSU
}

Edimar Brígido

Doutor em Filosofia. Professor de Ética e Filosofia no Centro Universitário Curitiba - UNICURITIBA.

ENTREVISTA

Marlene Teresinha Fuverki Suguimatsu é Desembargadora Presidente do Tribunal Regional do Trabalho do Paraná. Graduada em Direito (Faculdade de Direito de Curitiba-UNICURITIBA, 1984). Possui curso de Especialização em Direito Público (UFPR, 1989) e em Filosofia, com ênfase em Ética (PUCPR, 2003); Mestrado em Direito Econômico e Social (PUC-PR, 2002) e Doutorado em Direito Econômico e Socioambiental (PUC-PR). Exerce o cargo de Desembargadora Federal do Trabalho, no TRT $9^{a}$ Região; exerceu o cargo de Vice-Presidente do TRT 9a Região (2015-2017); foi diretora da Escola Judicial do TRT 9a Região (2012-2013); presidiu a Comissão de Uniformização de Jurisprudência do TRT $9^{a}$ Região (2006-2010 e 2014/2015); Professora nos cursos de pós-graduação em Direito do Trabalho na PUC-PR e UNICURITIBA e do Curso de Graduação em Direito do UNICURITIBA, de Direito Material do Trabalho I e II. Participou de cursos e eventos promovidos pela Comissão Ibero-Americana de Ética Judicial. Integrou o Projeto de Pesquisa "Regulação Econômica e Atuação Empresarial", Grupo "O Estado e a Atividade Econômica- o direito laboral em perspectiva, do PPGD-PUC/PR. É membro da Academia Paranaense de Direito do Trabalho. Integra o Grupo de Estudos sobre a Reforma Trabalhista no UNICURITIBA.

“O panorama não é animador, porque não é emancipatório, inclusivo e humanamente ético."

Marlene Suguimatsu

A Reforma Trabalhista de 2017 foi uma mudança na Consolidação das Leis de Trabalho (CLT), proposta pelo Presidente da República Michel Temer, com o propósito de modernizar as relações trabalhistas, combatendo o desemprego e a crise econômica no país. O Projeto de Lei 
começou a tramitar na Câmara dos Deputados em 23 de dezembro de 2016, sendo aprovado com 296 votos favoráveis e 177 contrários em 26 de abril de 2017. No Senado Federal a aprovação se deu em 11 de julho do mesmo ano, com 50 votos favoráveis e 26 contrários. A Lei no 13.467 de 2017 foi sancionada pelo Presidente da República no dia 13 de julho, sem vetos.

A Reforma Trabalhista foi polêmica, suscitando críticas por parte do Ministério Público do Trabalho, pela Organização Internacional do Trabalho, pelo Tribunal Superior do Trabalho, além das centrais sindicais e órgãos de classe. Desembargadora Marlene Suguimatsu, essas críticas foram superadas em alguma medida?

Marlene Suguimatsu - A Lei da Reforma, pela maneira como foi aprovada e por seu conteúdo, na maior parte desfavorável aos trabalhadores, efetivamente provocou dúvidas, inseguranças e críticas de vários setores da sociedade. Presencia-se, hoje, um cenário de profunda alteração na ordem legal que regulamenta as relações de trabalho, o que afeta diretamente o Direito do Trabalho e a Justiça do Trabalho. Essa foi a modificação nas leis do trabalho mais extensa e mais profunda depois da edição da CLT em 1943. A nova Lei retirou alguns direitos assegurados pela legislação anterior e pela jurisprudência construída por uma linha de pensamento mais progressista. Quando não retirou explicitamente, dificultou a obtenção de outros direitos ao afastar a intervenção sindical obrigatória em questões que envolvem tanto interesses individuais como coletivos ou a permitir a prevalência do negociado sobre o mínimo legislado (salvo o previsto no art. 611-A). Ainda, acentuou a possibilidade de precarização das relações de trabalho, seja pela facilitação dos contrários precários (como o intermitente ou por tempo parcial), seja pela ampliação das formas de contrato sem vínculo de emprego (como autônomo e mediante constituição de pessoa jurídica) ou pela ampliação sem limites das possibilidades de terceirização de serviços.

Não se pode afirmar que as críticas iniciais a essas e muitas outras questões estejam, em alguma medida, superadas, ao menos no que se refere aos direitos materiais assegurados aos trabalhadores. O Tribunal Superior do Trabalho editou Instrução Normativa que oferece parâmetros aos magistrados de primeiro e segundo graus no que se refere a alguns aspectos processuais, mais precisamente no ponto relativo à aplicabilidade temporal da nova lei. Quanto aos direitos materiais, que realmente afetarão a vida dos trabalhadores porque se traduzem em garantias mínimas, e ao final, normalmente em garantias pecuniárias, estes ainda dependem de 
muita discussão dentro dos processos, perante as Varas e os Tribunais do Trabalho do País e o próprio Tribunal Superior do Trabalho.

A Lei trouxe algumas novidades, como a regulamentação do teletrabalho e do trabalho intermitente, no campo do direito material, e a contagem de prazos em dias úteis e redução do valor do depósito recursal para pequenas empresas, no aspecto processual. Porém, falhou em muitos dos propósitos colocados como justificativas para a sua aprovação em tempo recorde. Entre as justificativas estavam a necessidade de modernizar a legislação do trabalho, o anseio por maior segurança jurídica, a geração de empregos e o combate à informalidade.

Os resultados práticos obtidos até agora com a nova Lei passam longe das expectativas depositadas naquelas e em outras justificativas: há quase 13 milhões de desempregados no País; a criação de novos empregos formais foi inexpressiva; segurança jurídica é quase inexistente, porque as dúvidas e as inseguranças se ampliaram substancialmente; e aspectos da CLT que realmente justificavam modernização continuam intactos no seu texto. O que se vê, na realidade, é a intensa limitação de acesso dos trabalhadores à Justiça, pelo receio da sucumbência recíproca, e uma advocacia em crise, pois advogados da área estão atônitos pela redução do número de demandas e pelo receio diante das incertezas de procedimentos, de direitos e de entendimentos jurisprudenciais. Há muito, ainda, a ser discutido e definido, até que se obtenham consensos no meio jurídico trabalhista.

Edimar Brígido - Doutora Marlene, do ponto de vista jurídico, constitucional e ético, existem aspectos da Reforma Trabalhista que ainda podem ser questionados?

Marlene Suguimatsu - Assim que se conheceu o texto final aprovado na Câmara de Deputados já foi possível avaliar algumas dimensões graves da Reforma, que se confirmaram com a aprovação da Lei no Senado e a sanção presidencial. Duas delas merecem destaque. A primeira, é que a Lei abalou o sistema clássico de proteção aos trabalhadores; a segunda é que a Lei ampliou substancialmente o sistema de proteção ao empregador.

No primeiro aspecto, a Lei não eliminou propriamente o sistema de proteção dos trabalhadores, mas promoveu profundo deslocamento no foco e na lógica da proteção. O Direito do Trabalho, na origem, nasceu e se desenvolveu a partir do reconhecimento social e jurídico da necessidade de se amparar minimamente a parte considerada mais vulnerável da relação contratual de trabalho, o trabalhador. Leis, princípios, doutrina e jurisprudência se construíram 
aos poucos e foram se ajustando a essa lógica, iniciada por volta do século XIX e intensificada no século XX. No Brasil, o sistema insipiente do início do século XX ganhou impulso com a CLT em 1943 e se afirmou com a Constituição Federal de 1988, que definiu como direitos fundamentais dos trabalhadores os arrolados principalmente nos vários incisos do art. $7^{o}$.

A partir da década de 1990, no entanto, já surgiriam medidas tendentes a romper com o compromisso protetivo do Direito do Trabalho. Foram medidas flexibilizadoras (como trabalho por tempo parcial, banco de horas, terceirização) impulsionadas em governo de tendência neoliberal, que não chegaram a afetar drasticamente o sistema tradicional, mas serviram de base para o que viria com a Lei da Reforma. Esta, sim, promoveu a grande mudança. Abalou o sistema tradicional do Direito do Trabalho por afetar as suas premissas principiológicas.

A rede de proteção que se instituiu em torno da gratuidade da justiça, da aplicação da norma mais favorável ao trabalhador e do acesso à justiça está comprometida. Os trabalhadores, hoje, estão inibidos de ajuizar ações de forma quase insuperável. Os riscos da sucumbência retiram a capacidade do Direito e da Justiça do Trabalho de oferecer proteção aos trabalhadores, na medida em que eventuais violações de direitos podem ser simplesmente suportadas por eles $e$ não levadas a apreciação do poder Judiciário para uma possível reparação. A redução de direitos direta e indireta acentua o enfraquecimento da proteção do trabalhador.

O segundo aspecto - ampliação do sistema de proteção aos empregadores - fica nítido em várias providências adotadas pelo legislador. A lei de proteção ao trabalho e ao trabalhador transformou-se, em grande medida, em lei de proteção ao empregador. Ampliaram-se as garantias de acesso à justiça (como o benefício da justiça gratuita a empregadores); surgiram garantias processuais (como a redução do valor do depósito recursal para pequenas empresas e dispensa de garantia da execução para entidades filantrópicas); instituíram-se garantias aos empregadores contra a própria Justiça do Trabalho (como imposição de limites à edição de súmulas pelos Tribunais, limites a análise do conteúdo de negociações coletivas pelos juízes e prevalência do negociado sobre o legislado) e criou-se proteção pelo fortalecimento da autonomia negocial (como negociação direta entre patrões e empregados em vários direitos, afastamento da participação dos sindicatos e o enfraquecimento destes, com a retirada da contribuição sindical obrigatória).

A percepção de que a nova Lei foi prejudicial aos trabalhadores, aos sindicatos, à Justiça e ao próprio Direito do Trabalho levou a algumas reações. Internamente, por meio de mobilizações nacionais e locais de juízes e suas associações, por congressos, simpósios e muitas 
produções literárias. Externamente, e não obstante a posição da mídia tradicional, que passou a criticar fortemente a magistratura atribuindo-lhe responsabilidade por eventual fracasso da Reforma, vieram reações de vários setores, que ajuizaram ações de declaração de inconstitucionalidade perante o STF. Há, atualmente, mais de 20 ações de inconstitucionalidade em tramitação no STF, ajuizadas tanto pelo Ministério Público do Trabalho (que questiona honorários de sucumbência e justiça gratuita), pela $O A B$ e entidades sindicais (como as que questionam o fim da contribuição sindical obrigatória), pela Associação Nacional dos Magistrados do Trabalho - ANAMATRA (quanto a correção de depósitos recursais e tarifação dos danos morais), Confederação de Trabalhadores Metalúrgicos (para discutir trabalho de gestantes e lactantes em atividades insalubres), entre outras.

Como se observa, muitos aspectos da Reforma já foram e muitos ainda podem ser questionados juridicamente, seja por ação direta perante o STF ou no âmbito de cada processo que for ajuizado nas Varas do Trabalho e Tribunais, quando a parte pode discutir possíveis inconstitucionalidades ou ofensa a convenções internacionais ratificadas pelo Brasil. Eventual pacificação sobre todos esses temas jurídicos e constitucionais, pelo que se vê, está longe de ocorrer.

Do ponto de vista ético, a situação parece ainda mais delicada. A visão do trabalho como um dos elementos do processo de produção leva, necessariamente, a considerações sobre economia e como ela se relaciona com a ética, sob o viés do bem-estar humano. Amarthya Sen, prêmio Nobel de economia, demonstra como ao longo do tempo economia e ética se distanciaram tão gravemente, ao ponto de gerar uma das principais deficiências da teoria econômica contemporânea e que a economia pode tornar-se mais produtiva de dispensar "atenção maior e mais explícita às considerações éticas que moldam o comportamento e o juízo humano”. As relações entre ética e o desempenho econômico dos indivíduos, empresas e nações passam pela avaliação sobre o que fazer quando direitos individuais, como direitos humanos e fundamentais se chocam com interesses econômicos empresariais e até de projetos nacionais.

Questões econômicas são, sim, questões de praticidade, eficiência, lucratividade e exequibilidade, mas também são questões de justiça, ética, bem-estar humano e solidariedade, pois todas decorrem das relações entre as pessoas e a elas devem estar voltadas. Uma ética econômica ou política que se pretenda verdadeiramente humana supõe consciência de nossas responsabilidades, pessoal ou coletiva. 
Como afirmou Edgar Morin, "de um lado, cada um deve reconhecer-se responsável por suas palavras, por seus escritos, por seus atos" e há uma responsabilidade oriunda de nossa comunidade, que tem a ver até mesmo com o destino planetário. Será esta responsabilidade que nos relembrará, sempre, "nossa parcela de responsabilidade nesse destino comum, não somente no que diz respeito ao presente, mas também no futuro”. Neste aspecto, é fundamental lembrar a enorme responsabilidade dos legisladores e os que contribuíram para a elaboração e aprovação de uma lei do trabalho orientada por um viés quase absolutamente econômico e minimamente moral e ético, que além de suprimir direitos de trabalhadores direta ou indiretamente, permitiu eliminá-los ou reduzi-los pela via negocial direta ou coletiva, limitou substancialmente o seu acesso à justiça e fragilizou os mecanismos de proteção conquistados ao longo da história com muito esforço e sofrimento. Não se pode fazer do necessário progresso econômico uma forma de regressão bárbara e de desconsideração do pouco de humano que ainda nos resta. Esse parece ser o principal desafio.

Edimar Brígido - Tendo passado um ano desde a aprovação da Reforma Trabalhista, quais as principais mudanças decorrentes da flexibilização da Consolidação das Leis do Trabalho (CLT)? Essas mudanças beneficiaram a classe trabalhadora e geraram mais oferta de empregos?

Marlene Suguimatsu - Os resultados práticos da Lei da Reforma Trabalhista, após um ano de sua vigência, mostram-se muito aquém dos resultados esperados, se consideradas as justificativas apresentadas para a sua aprovação. Não se promoveu a propalada modernização da CLT, especialmente no campo do direito material do trabalho; a prevalência do negociado sobre o legislado mostra-se contraditória, pois passou a ideia de fortalecimento dos poderes dos sindicatos, quando estes, na realidade, enfraqueceram-se absurdamente com a perda de sua principal fonte de arrecadação e com o seu afastamento de muitas questões, inclusive de interesse coletivo, que poderão ser negociadas diretamente entre empregados e patrões; os novos modelos de contratos adotados foram todos prejudiciais aos trabalhadores, por dificultar o reconhecimento de vínculo de emprego, afastar o vínculo ou precarizar as relações; a redução no conceito de salário tende a retirar a garantia de irredutibilidade salarial, a empobrecer gradativamente os trabalhadores pela queda nos níveis remuneratórios, além de permitir que empregadores se apropriem de valores destinados ao FGTS, Previdência Social e Imposto de Renda, importantes fontes de arrecadação pública. 
Por fim, dados estatísticos demonstram aumento do desemprego e insipiente criação de novos empregos, além de limitação ao acesso dos trabalhadores à Justiça e as formas flexibilizadas de contratos e de direitos tendem, como mencionado a promover empobrecimento geral pela cultura da baixa remuneração, o que se refletirá na dificuldade de acesso aos bens disponíveis.

Edimar Brígido - A Reforma Trabalhista permite que sejam realizados acordos coletivos entre patrões e empregados. Essa flexibilização não fere as garantias sociais e os direitos assegurados aos trabalhadores pela Constituição Federal?

Marlene Suguimatsu - A Constituição Federal de 1988 atribuiu aos sindicatos a tarefa de representar e defender os interesses dos trabalhadores, especialmente no que se refere aos interesses coletivos das categorias. Essa foi uma das maiores conquistas sociais assentadas na Constituição. Dispensar a participação sindical de negociações, como algumas relativas à compensação de jornada, significa consagrar o desequilíbrio natural entre as partes, retirar a proteção assegurada justamente pela participação sindical, que entre outras finalidades, atua para garantir a necessária equivalência entre os contratantes e lançar os trabalhadores a sua própria sorte, porque terão que enfrentar o poder social e econômico dos empregadores e extrair dessa relação de desigualdade alguma vantagem em termos de direitos.

A Constituição assegura o mínimo em termos de proteção dos trabalhadores. A negociação coletiva existe justamente para ampliar esse patamar mínimo e esse objetivo se cumpre com as lutas, mecanismos de defesa e negociações sindicais. Retirar esse mecanismo implica condenar as relações de trabalho à estagnação, e o risco de se permitir até involução de direitos, dependendo do grau de pressão que o trabalhador sofra para abrir mão de direitos em troca da permanência no emprego.

Edimar Brígido - A Reforma fere em alguma medida a dignidade humana, ou seria exagero pensar dessa forma?

Marlene Suguimatsu - Há alguns pontos da Reforma que afetam de maneira muito clara as bases para uma vida digna. Dignidade da pessoa humana remete a um tema complexo, ligado a valores inerentes ao ser humano. E como o trabalho é uma projeção da capacidade humana, da mente e do corpo humanos, é uma categoria intrínseca ao homem, inseparável dele, está 
diretamente associado à dignidade. Quando Lei da Reforma permite, por exemplo, que gestantes e lactantes trabalhem em ambiente insalubre, sujeitas a riscos a sua integridade física e quem sabe, a do feto ou do recém nascido, talvez permita ameaça ou ofensa a dignidade da mãe trabalhadora e do filho; quando permite que nas terceirizações de serviços empresas contratante e contratada é que decidam se querem ou não assegurar o direito dos trabalhadores terceirizados de receber salários iguais aos dos empregados diretos, também pode estar negando tratamento digno aos terceirizados; ou quando permite que o trabalhador intermitente, durante o período de inatividade, nada receba do empregador ainda que não consiga outra fonte de subsistência no período, a lei estará permitindo que o empregador afete as bases mínimas de uma vida digna de seu empregado. A Lei da reforma, que foi apresentada como remédio para males financeiros, políticos e sociais do País, poderá se transformar no próprio veneno por ser prejudicial e em muitos pontos perversa aos trabalhadores. Em alguma medida poderá afetar a dignidade humana.

Edimar Brígido - A nova legislação fez reduzir o número de reclamatórias trabalhistas que chegam até a Justiça do Trabalho?

Marlene Suguimatsu - Num primeiro momento, quando se tomou conhecimento da Lei e até a sua entrada em vigor ocorreu crescimento impactante no volume de ações, especialmente entre outubro e início de novembro/2017, o que significou mais do que o dobro do número ajuizando nos meses anteriores. Em um segundo momento, com a entrada em vigor, houve redução significativa. Nos primeiros meses após a Reforma, em dezembro/2017 e janeiro/2018, o ajuizamento ficou num patamar de aproximadamente $10 \%$ do ano anterior. A partir de fevereiro/2018, contudo, na jurisdição do Tribunal do Paraná os números foram gradativamente subindo, embora não tenham alcançado o patamar verificado no mesmo período de janeiro a outubro/2017 e nem se saiba quando e como irá estabilizar. De acordo com a última estatística, a redução, em média, considerado o mesmo período, permanece em torno de $45 \%$ das ações ajuizadas no ano anterior. É fácil perceber que essa redução ocorre não por força de um movimento natural de ajuste, mas motivada pelo medo dos trabalhadores de ajuizar ação para discutir eventual violação de direitos e saírem devedores da Justiça por força da sucumbência recíproca, das custas do processo e das ameaças de multas para a hipótese de insucesso na demanda. 
O receio de ajuizar ação e se transformar em devedor da Justiça é um dos principais fatores de inibição. Se o objetivo foi reduzir o número de ações judiciais pela inibição e pelo medo, a Reforma Trabalhista foi o mecanismo adequado a esse propósito.

Edimar Brígido - Após cinco sessões, o Supremo decidiu, com um placar de 7 votos a 4, que a terceirização irrestrita é constitucional. Como a senhora analisa essa decisão?

Marlene Suguimatsu - A terceirização que se construiu até a Lei da reforma significou a transferência para outrem de atividades consideradas secundárias por uma empresa. Aos poucos foi-se autorizando o exercício de atividades de suporte por uma empresa terceirizada, permanecendo a empresa tomadora com sua atividade central. Algumas terceirizações foram sendo autorizadas por lei e outras foram encontrando abertura na jurisprudência do TST, que há muito tempo firmou posição no sentido de não permitir na atividade essencial ou atividade fim.

A Lei da Reforma, no entanto, ampliou sem limites as possibilidades de terceirizar atividades. O STF respaldou a posição assumida pelo legislador da Reforma e hoje na iniciativa privada é possível terceirizar qualquer atividade; no setor público, remanescem algumas restrições.

É sabido que os principais objetivos desse modelo são a maximização de lucros e a obtenção de maior produtividade, além do discurso da qualidade do produto ou do serviço. Em nome desses objetivos, estritamente econômicos, sacrificam-se vários outros elementos e aspectos inerentes ao trabalho humano. Não se considerou a valorização do trabalho humano como um dos fundamentos da República e da ordem econômica e social. Não se preocupou com a possível precarização das relações laborais pela baixa remuneração, comum nesse modelo, nem pelas condições ameaçadoras a saúde, à higiene e a segurança. Não sensibilizou a possibilidade de oposição entre trabalhadores terceirizados e diretamente contratados e a maior valorização destes, nem as práticas de contratos descontínuos e rápidos, além da fragmentação da empresa, a dispersão dos trabalhadores e a fragilização dos sindicatos, para citar apenas algumas consequências. Há séria ameaça, também, ao próprio conceito de empregado e de empregador.

Modernizar, atualizar, garantir espaços no mercado, assegurar competitividade de serviços e produtos, tudo é compreensível e pode ser ajustado. Da forma como hoje se solucionou, pela Lei e pelo entendimento do STF, garantiram-se ao setor econômico todas essas possibilidades, mas impondo aos trabalhadores altíssimo custo em termos de qualidade do emprego, valor do trabalho, segurança e saúde e inserção social. 
Privilegiou-se o poder econômico, em detrimento da força de trabalho, que deverá contentar-se com o emprego e com pouca perspectiva de valorização e participação naquilo que a sociedade oferece a poucos.

Edimar Brígido - A senhora acredita que o Brasil atravessa um período marcado pelo retrocesso social e por perda de direitos adquiridos?

Marlene Suguimatsu - Na minha concepção, pelo fato da Reforma Trabalhista ter promovido modernização apenas insipiente, ter suprimido e permitido supressão direitos, pelo potencial de acentuar as desigualdades inerentes às relações de trabalho, ter consagrado práticas de precarização e desvalorização do trabalho humano, não ter obtido êxito na promessa de estimular a ampliação de empregos, ter gerado enfraquecimento das entidades sindicais e ter dificultado de maneira quase incontornável o acesso do trabalhador à Justiça, entre outras consequências prejudiciais, especialmente do ponto de vista do direito material do trabalho, lamentavelmente enfrentamos movimento de retrocesso social.

É preciso preservar o que restou, se não for possível em curto prazo resgatar as perdas registradas. Para isso a Constituição Federal será o norte.

Edimar Brígido - Para concluir a nossa conversa, a senhora poderia, enquanto presidente do Tribunal Regional do Trabalho, nos falar um pouco a respeito das suas expectativas a respeito das relações de trabalho daqui para frente?

Marlene Suguimatsu - Nesse panorama de um ano após a Reforma alguns dados são importantes: mais de 20 ações discutindo inconstitucionalidades na Lei tramitam perante o STF; há algumas normas disciplinadoras, oriundas do Ministério do Trabalho, mas sem caráter vinculativo; nas Varas e Tribunais do Trabalho, inúmeras decisões são proferidas, muitas divergências, e grandes distâncias de algum consenso em tempo próximo; há quase 13 milhões de desempregados no país e não houve criação expressiva de novos empregos; os trabalhadores estão inibidos e a maioria não procura o Poder Judiciário; os empresários não tem muita segurança, porque as interpretações nos Tribunais são divergentes e a própria Lei dificultou a elaboração de súmulas capazes de uniformizar a jurisprudência; a advocacia trabalhista está em crise.

O que esperar das futuras relações de trabalho, do Direito e da Justiça do Trabalho? Neste aspecto, especula-se mais intensamente transformações na própria estrutura da Justiça do 
Trabalho; propõe-se um estranho e inaceitável modelo diferenciado da chamada "Carteira de Trabalho Verde-Amarelo”, que, pelo divulgado, seria uma forma de flexibilizar ainda mais a lei trabalhista, para permitir que trabalhadores jovens decidam "se preferem" um contrato mais precário ou mais protegido, como se fosse possível relegar a garantia de direitos mínimos às preferências de trabalhadores e empregadores; optou-se por liberar contratos terceirizados sem limites e dar a prerrogativa aos empregadores de escolher a quem contratar, a forma como se quer contratar (com vínculo, autônomo, como pessoa jurídica, ou terceirizado) e o quanto se quer pagar, especialmente nas terceirizações, porque se as empresas contratantes decidirem, não haverá equivalência salarial entre terceirizados e trabalhadores contratados diretamente.

O panorama não é animador, porque não é emancipatório, inclusivo e humanamente ético. 